\title{
Unplanned attendances of cancer patients to an outpatient unit in a low-income country: A prospective study from Sudan
}

\begin{tabular}{|c|c|}
\hline \multicolumn{2}{|c|}{$\begin{array}{l}\text { Authors: } \\
\text { Moawia M.A. Elhassan }{ }^{1} \text { (1) } \\
\text { Safa I.H. Taha }{ }^{2} \\
\text { Maha M.A. Maatoug }\end{array}$} \\
\hline \multicolumn{2}{|c|}{$\begin{array}{l}\text { Affiliations: } \\
{ }^{1} \text { Department of Clinical } \\
\text { Oncology, National Cancer } \\
\text { Institute, University of Gezira, } \\
\text { Wad Medani, Sudan }\end{array}$} \\
\hline \multicolumn{2}{|c|}{$\begin{array}{l}\text { Department of Clinical } \\
\text { Pharmacy, Faculty of } \\
\text { Pharmacy, University of } \\
\text { Gezira, Wad Medani, Sudan }\end{array}$} \\
\hline \multicolumn{2}{|c|}{$\begin{array}{l}\text { Corresponding author: } \\
\text { Moawia Elhassan, } \\
\text { moawia2@gmail.com }\end{array}$} \\
\hline \multicolumn{2}{|c|}{$\begin{array}{l}\text { Dates: } \\
\text { Received: } 10 \text { Mar. } 2020 \\
\text { Accepted: } 21 \text { July } 2020 \\
\text { Published: } 15 \text { Sept. } 2020\end{array}$} \\
\hline \multicolumn{2}{|c|}{$\begin{array}{l}\text { How to cite this article: } \\
\text { Elhassan MMA, Taha SIH, } \\
\text { Maatoug MMA. Unplanned } \\
\text { attendances of cancer } \\
\text { patients to an outpatient unit } \\
\text { in a low-income country: A } \\
\text { prospective study from } \\
\text { Sudan. S. Afr. j. oncol. } \\
\text { 2020;4(0), a126. https://doi. } \\
\text { org/10.4102/sajo.v4i0.126 }\end{array}$} \\
\hline \multicolumn{2}{|c|}{$\begin{array}{l}\text { Copyright: } \\
\text { ( 2020. The Authors. } \\
\text { Licensee: AOSIS. This } \\
\text { work is licensed under } \\
\text { the Creative Commons } \\
\text { Attribution License. }\end{array}$} \\
\hline \multicolumn{2}{|l|}{ Read online: } \\
\hline 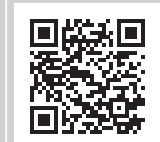 & $\begin{array}{l}\text { Scan this QR } \\
\text { code with your } \\
\text { smart phone or } \\
\text { mobile device } \\
\text { to read online. }\end{array}$ \\
\hline
\end{tabular}

Background: Studies of unplanned attendances of cancer patients to outpatient oncology units in limited-resource settings are rare.

Aim: The primary aim of the study was to determine the cause of unplanned visits of cancer patients to an outpatient clinic in a limited-resource setting. A secondary aim was to provide an overview of the demographic, clinical characteristics and outcomes of this cohort of patients.

Setting: Outpatient clinic at National Cancer Institute, Sudan.

Methods: This prospective cross-sectional study was conducted between October 2018 and February 2019. Clinical data of patients who presented without an appointment during the study period were reviewed.

Results: Out of 5957 patients' attendances to the outpatient clinic during the study period, $70 \%$ were planned and 30\% were unplanned. A total of 642 patients made the unplanned visits to the outpatient department. Only 501 of these patients met the criteria for inclusion in the study. The purpose of the unplanned visits included: clinical assessment (75\%), giving results of investigations when patients missed their planned appointment $(20 \%)$ and refilling of prescription medication (5\%). Most of the patients were females (64.5\%), and the most common tumour site was the breast $(26.7 \%)$, followed by the gastrointestinal tract $(18.4 \%)$. The majority $(63.5 \%)$ of the patients had loco-regional disease and $24.5 \%$ had stage IV disease. At the time of this study, only half of the cases were on active oncological treatment. The most frequent presenting complaints at unplanned visits were uncontrolled pain (39\%), vomiting (11\%) and fever (9\%). Ninety-five patients (19\%) were hospitalised after an unplanned presentation.

Conclusions: Thirty percent of patients' attendances to the outpatient oncology clinic were unplanned. Uncontrolled pain was the most frequent symptom (39\%) that prompted patients to attend the outpatient unit without an appointment. We recommend that the adequacy of cancer pain management in our setting should be systematically evaluated and that effective cancer pain management programs should be developed to prevent unplanned visits prompted by uncontrolled pain.

Keywords: unscheduled visits; unplanned presentations; appointments and schedules; pain; developing countries.

\section{Introduction}

Worldwide, approximately 18.1 million new cancer cases and 9.6 million cancer deaths occurred in 2018. ${ }^{1}$ The World Health Organisation (WHO) estimates that by 2040, this will increase to 29.5 million new cancer diagnoses and 16.5 million cancer-related deaths annually. ${ }^{2}$ Approximately $70 \%$ of cancer deaths in the world occur in low- and middle-income countries (LMICs), a fact that has forced health authorities in LMICs to acknowledge cancer as a high-priority health problem. ${ }^{1}$ Unfortunately, these health systems often have a high burden of other equally pressing health issues to contend with including infectious diseases, violence, malnutrition and mother and child health. ${ }^{3}$

Sudan is a low-income country in sub-Saharan Africa with a population of approximately 40 million people. Approximately half of the population is living below the poverty line. The Sudanese government spends about $8.43 \%$ of its annual gross domestic product (GDP) on healthcare. ${ }^{4}$ Healthcare in Sudan is delivered at three levels. At the apex are teaching, general and specialised hospitals providing secondary and tertiary healthcare. In the secondary level 
are the rural hospitals providing secondary care and diagnostic facilities. Primary level care is provided through primary healthcare unit, dressing stations and family health centres. Despite the significant burden of communicable diseases, cancer has been amongst the top 10 causes of hospital admissions in Sudan and ranks as the third leading cause of death after malaria and pneumonia. ${ }^{5}$ The National Health Insurance Fund (NHI) covers approximately $43.8 \%$ of the population of Sudan. Membership of NHI is compulsory for the formal sector, whilst it is voluntary for the informal sector and small companies. The subscriber unit is the family and beneficiaries include the principal member, spouse, children and parents. The insured and non-insured cancer patients are treated in the same public hospitals. Khartoum Oncology Hospital and the National Cancer Institute in Wad Medani are the only two specialised state cancer centres in the country providing both chemotherapy and radiation therapy treatments to cancer patients. More recently, the government has established five new chemotherapy units attached to five state hospitals. Geographic distribution of cancer treatment centres in Sudan is shown in Figure 1. Chemotherapy, radiation therapy and supportive medications are available without cost to Sudanese citizens at public cancer centres regardless of insurance status. However, for the many cancer patients without adequate health insurance coverage, limited personal finances can be a significant barrier to accessing surgical interventions and diagnostic investigations. For cancer patients receiving treatment at the $\mathrm{NCI}$, charity organisations such as Sudanese Zakat Chamber, which is a form of Islamic charity, and The Friends of Cancer Patients Society are covering expenses for investigations for uninsured patients with limited personal finances.

In Sudan, the management of cancer patients faces major challenges: weak healthcare infrastructure, low numbers of oncology healthcare professional and a paucity of comprehensive cancer treatment centres. ${ }^{6}$ Moreover, the majority of cancer patients have locally advanced or metastatic disease at presentation. ${ }^{7,8,9,10,11,12}$ These challenges along with lack of access to palliative care services may result in higher numbers of unplanned attendances to outpatient units for palliation of uncontrolled symptoms, management of treatment-related side effects and end of life care. Therefore, outpatient units are often overcrowded and waiting periods for care can be long and uncomfortable. Unplanned attendances also add to the strain on human resources. A previous study assessing the nature of unscheduled visits by cancer patients in South Africa showed that pain was the most common presenting complaint and the majority of patients had locally advanced or metastatic diseases. ${ }^{13}$ In a Canadian cohort of cancer survivors, Lebel and colleagues found a correlation between fear of cancer recurrence and unplanned outpatient or emergency room visits. ${ }^{14}$

There is limited data published on unplanned visits to oncology outpatient departments in Africa $^{13}$ and to our knowledge there is no previous study on this subject conducted in Sudan. Therefore, this study was undertaken to assess the prevalence, main reasons for and outcomes of unplanned visits of cancer patients to the outpatient clinic at the National Cancer Institute (NCI), Sudan. The information obtained from this study may aid in improving the provision of high-quality care to cancer patients and potentially avoid unplanned visits and hospital admission.

\section{Methods}

\section{Setting}

The National Cancer Institute (NCI) is an 80-bed hospital affiliated to the University of Gezira specialising in the diagnosis and treatment of cancer patients. It is located in Wad Medani city, the capital of Gezira state, which serves the whole Gezira state and nearby states.

Consultations at outpatient oncology clinics are by appointment. These clinics, general oncology clinic, provide specialist consultation to cancer patients with all tumour sites during week days from 8:00 AM to 15:00 PM. The trained receptionist makes appointments in a diary and patients get cards to keep track of their appointment. There is no system to send out reminders to patients telephonically or by a message system.

\section{Study design}

We performed a prospective, cross-sectional study to evaluate the prevalent, reasons for and outcomes of unplanned visits to the outpatient oncology clinic at NCI over a 4-month period from October 2018 to February 2019.

The primary aim of the study was to determine the cause of unplanned visits. The complaints that prompted patients to attend for clinical assessment were subdivided as follows: symptoms related to progression of disease or uncontrolled advanced disease, symptoms secondary to side effects of cancer treatment and symptoms related to medical comorbidities. A secondary aim was to provide an overview of the demographic, clinical characteristics and outcomes of this cohort of patients.

\section{Data collection}

All cancer patients who had been treated at the NCI and made unplanned visits, which are non-booked clinic visits by patients, to the outpatient unit during the study period were identified. Patients $<16$ years of age and patients who refused to participate were excluded from the study. A predesigned paper-based questionnaire containing 26 questions was developed by the principal investigator. The questionnaire was submitted to a panel of three experts to review the content accuracy and internal validity. It was then piloted on 10 patients and modifications were made according to the suggestions. Questionnaire was completed by a research assistant based on patients' answers. The data collected included: Demographics (age, sex and residence), reason(s) for attendance, clinical variables (presenting complains, 


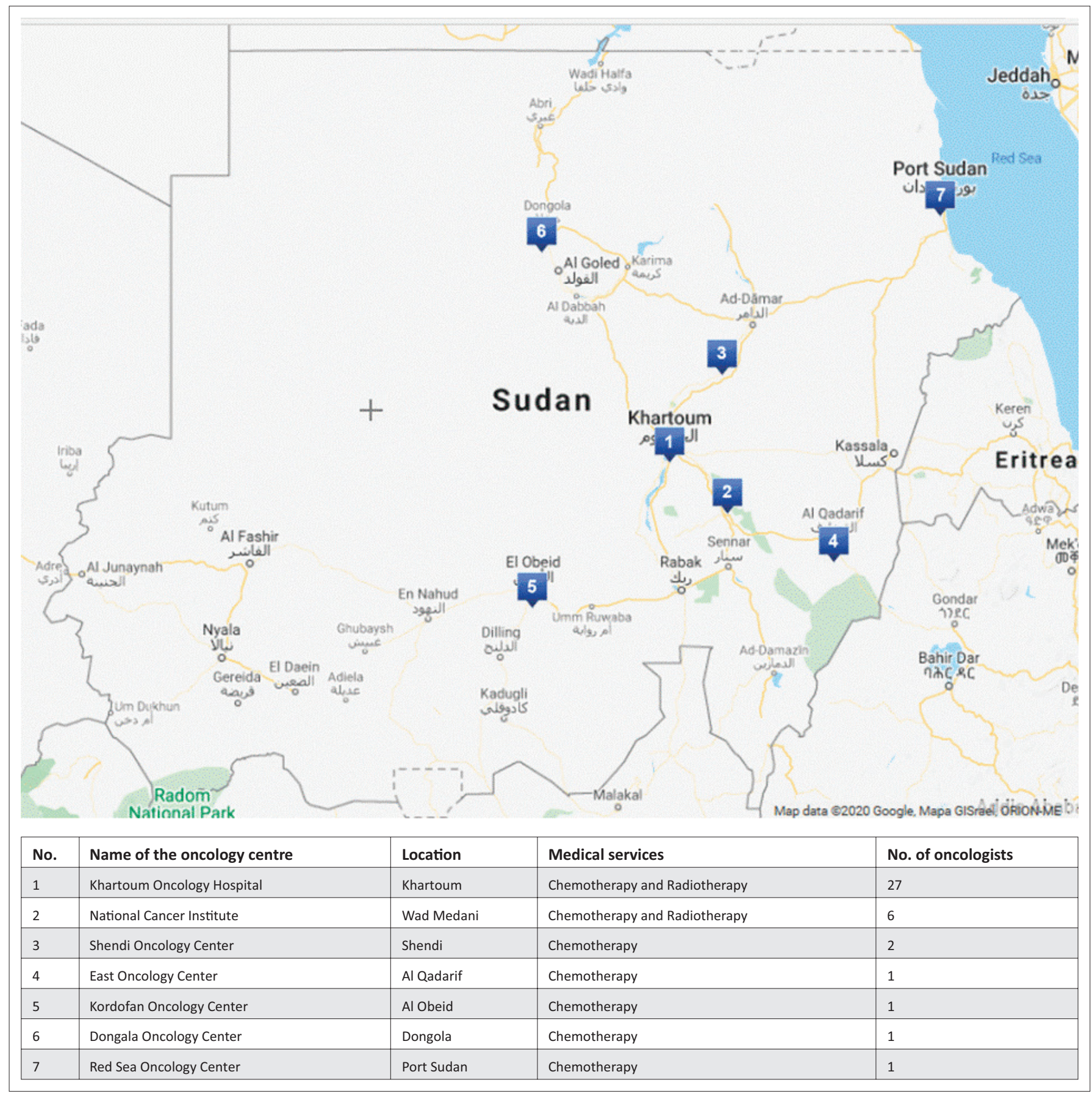

FIGURE 1: Geographic distribution of cancer treatment centres in Sudan.

primary cancer site, stage and comorbidities), treatment variables, dates of previous unplanned visits and outcome of the visit. Patients were interviewed once during the study period. Medical records were used to obtain specific information only when necessary. Verbal consent was obtained from patients prior to their inclusion in the study.

\section{Statistical analysis}

Data were entered into and analysed using Statistical Package for Social Science (SPSS) version 24. Categorical variables are presented as frequencies and percentages and continuous data are presented as means (standard deviation) or median values (range) depending on normality.

\section{Ethical consideration}

Ethical approval for this prospective study was obtained from the ethical committee at the Faculty of Medicine, University of Gezira. All data were collected anonymously. Ethical Clearance was received on 15-10-2018.

\section{Results}

Out of 5957 patient attendances to the outpatient unit at the NCI during the study period, $4170(70 \%)$ were planned and 1787 (30\%) were unplanned attendances. The 1787 unplanned visits were made by a total of 642 patients. Of these, 501 patients met the criteria for inclusion in this study. 
TABLE 1: Demographic and clinical characteristics $(N=501)$.

\begin{tabular}{|c|c|c|}
\hline Clinical feature & Frequency & Percentage \\
\hline \multicolumn{3}{|l|}{ Gender } \\
\hline Male & 178 & 35.5 \\
\hline Female & 323 & 64.5 \\
\hline \multicolumn{3}{|l|}{ Residence } \\
\hline Rural & 368 & 73.5 \\
\hline Urban & 133 & 26.5 \\
\hline \multicolumn{3}{|l|}{ Marital status } \\
\hline Married & 360 & 71.9 \\
\hline Single & 65 & 13.0 \\
\hline Widowed & 57 & 11.4 \\
\hline Divorced & 19 & 3.8 \\
\hline \multicolumn{3}{|l|}{ Occupation } \\
\hline Employed & 202 & 40.3 \\
\hline Unemployed & 299 & 59.7 \\
\hline \multicolumn{3}{|l|}{ Health insurance } \\
\hline Yes & 380 & 75.8 \\
\hline No & 121 & 24.2 \\
\hline \multicolumn{3}{|c|}{ Primary cancer diagnosis } \\
\hline Breast & 134 & 26.7 \\
\hline Gastrointestinal tract & 92 & 18.4 \\
\hline Head-neck & 70 & 14.0 \\
\hline Gynaecological & 69 & 13.7 \\
\hline Urology & 48 & 9.6 \\
\hline Leukemia & 28 & 5.6 \\
\hline Lymphoma & 23 & 4.6 \\
\hline Lung & 10 & 2.0 \\
\hline Other & 28 & 5.6 \\
\hline \multicolumn{3}{|l|}{ Comorbidities } \\
\hline No & 402 & 80.2 \\
\hline Yes & 99 & 19.8 \\
\hline \multicolumn{3}{|l|}{ Disease status } \\
\hline Local regional & 318 & 63.5 \\
\hline Metastatic & 122 & 24.5 \\
\hline Clear from disease & 61 & 12.0 \\
\hline
\end{tabular}

The reasons for exclusion were refusal to participate (56 patients) and age below 16 years ( 85 patients). The general characteristics of the study population are presented in Table 1. The mean and median ages were 55.5 years (SD 14.9) and 52 years (range 19-95 years), respectively. The male to female ratio was 1:2. The most common tumour site was breast (26.7\%), followed by gastrointestinal tract (18.4) and head and neck (14\%). Nearly two-thirds (63.5\%) of the cohort had loco-regional disease, $24.5 \%$ had metastatic disease and $12 \%$ were clear of disease at the time of inclusion in this study. Among patients with stage IV cancer, bone was the most frequent site of metastasis (45\%) as shown in Figure 2.

Nearly all (99.2 \%) the patients making unplanned attendances were self-referrals. The reasons given for the unplanned visits were the following: needing clinical assessment ( $n=376,75 \%$ ), wanting results of investigations after missing their scheduled appointment $(n=98,20 \%)$ and needing prescription refilled $(n=27,5 \%)$. Of 376 patients who presented for clinical assessment: 270 (72\%) had cancer-related symptoms, 69 (18\%) had chemotherapy and / or radiotherapy related side-effects, and $37(10 \%)$ had complaints related to other medical conditions such as

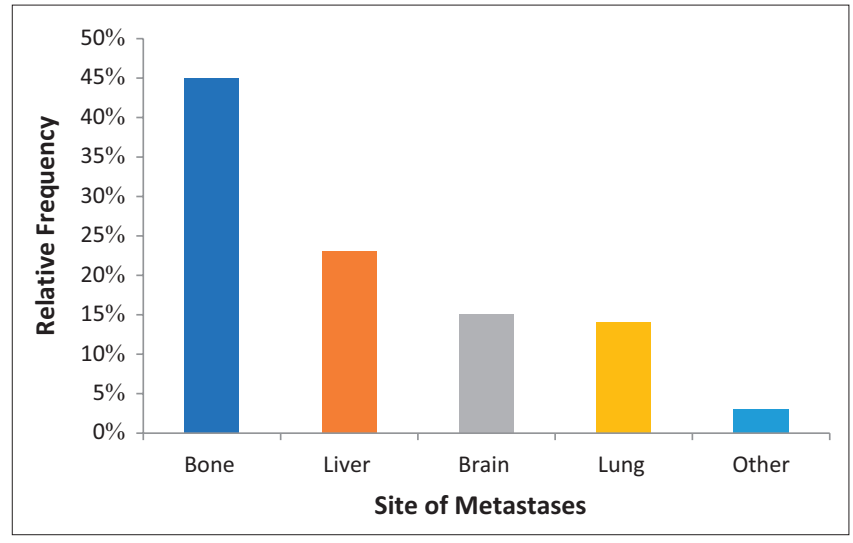

FIGURE 2: Distribution of patients with stage IV disease $(n=122)$ according to sites of metastases.

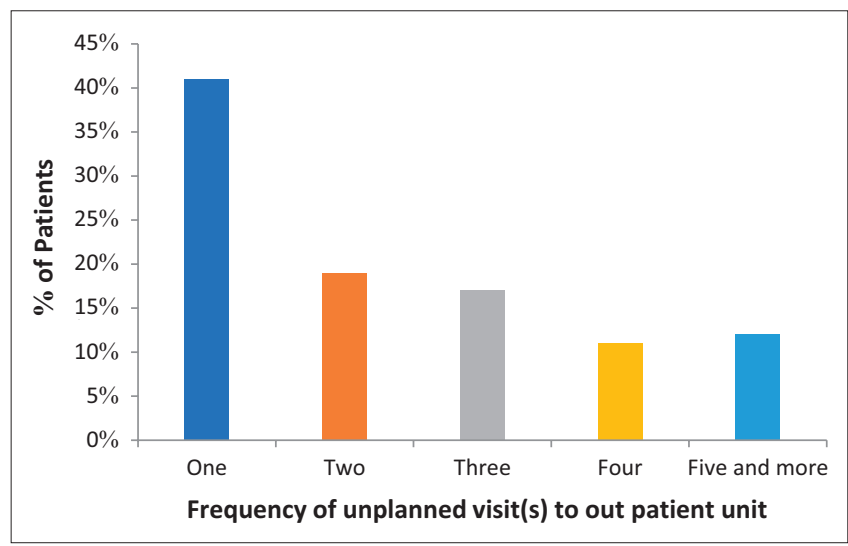

FIGURE 3: Frequency of unplanned visits to outpatient unit by cancer patients (501) during the study period.

malaria, lower urinary tract infections (LUTI) and peptic ulcer disease. Only $56 \%$ of patients who visited the outpatient unit for clinical assessment had new symptoms and/or signs. The majority (59\%) of the study population had a history of previous unplanned visits to the outpatient unit during the study period as shown in Figure 3.

Amongst the 27 patients who presented to the outpatient unit unplanned needing prescription refilled, a total of 19 (60\%) filled an opioid analgesic prescription and 8 (40\%) filled oral hormonal therapy prescription. The majority of $(90 \%)$ patients needing prescriptions refilled had locally advanced or metastatic disease and only $10 \%$ were clear at time of study. All clear patients needing prescription filled oral hormonal therapy.

Diabetes mellitus (8.8\%) and hypertension (8.8\%) were the most frequent comorbidities occurring in our study population. Asthma and coronary artery disease were found in $2 \%$ and $1 \%$, respectively. Out of 99 patients who had comorbidities, the reasons of unplanned visits in 30\% were complaints related to their comorbidities or other medical conditions such as malaria and LUTI.

Of the $253(50.5 \%)$ patients making unplanned visits who were on active oncological treatment, 97 (38.3\%) were on chemotherapy, 90 (35.6\%) on radiotherapy and $66(26.1 \%)$ 
TABLE 2: Most common presenting complaint of cancer patients prompting unplanned visits to the outpatient unit at the National Cancer Institute, Sudan.

\begin{tabular}{lcc}
\hline Chief complaints & Frequency & Percentage (\%) \\
\hline Pain & 197 & 39 \\
Vomiting & 56 & 11 \\
Fever & 48 & 9 \\
Cough & 27 & 5 \\
Diarrhoea & 26 & 5 \\
Lower urinary tract symptoms & 26 & 5 \\
Fatigue & 17 & 3 \\
Other complaints & 19 & 4 \\
Abdominal distension & 14 & 3 \\
Constipation & 14 & 3 \\
Neurological disturbance & 13 & 3 \\
Skin rash or ulceration & 12 & 2 \\
Anorexia & 11 & 2 \\
Dyspnoea & 11 & 2 \\
Oral mucositis & 10 & 2 \\
Numbness & 6 & 1 \\
Dysphagia & 3 & 1 \\
\hline
\end{tabular}

TABLE 3: Distribution of patients according to sites and types of pain.

\begin{tabular}{|c|c|c|c|c|c|c|}
\hline \multirow[t]{3}{*}{ Site of pain } & \multicolumn{4}{|c|}{ Types of pain } & \multicolumn{2}{|c|}{ Totals } \\
\hline & \multicolumn{2}{|c|}{ Acute } & \multicolumn{2}{|c|}{ Chronic } & \multirow[t]{2}{*}{$N$} & \multirow[t]{2}{*}{$\%$} \\
\hline & $n$ & $\%$ & $n$ & $\%$ & & \\
\hline Abdomen & 30 & 42 & 50 & 40 & 80 & 41 \\
\hline Bone & 19 & 26 & 45 & 36 & 64 & 32 \\
\hline Chest & 4 & 5 & 15 & 12 & 19 & 10 \\
\hline Headache & 12 & 17 & 6 & 5 & 18 & 9 \\
\hline Others & 7 & 10 & 9 & 7 & 16 & 8 \\
\hline Total & 72 & 100 & 125 & 100 & 197 & 100 \\
\hline
\end{tabular}

on hormone therapy. The reasons given for the unplanned visits in this group of patients: needing clinical assessment $(n=209)$, wanting results of investigations after missing their scheduled appointment $(n=26)$ and needing prescriptions refilled $(n=18)$. The symptoms that prompted unplanned attendances among patients on active oncological treatment were tumour-related symptoms in 127 patients, treatmentrelated side-effects in 69 patients and complaints related to other medical conditions in 13 patients. Pain was the most frequently reported symptoms $(n=98)$, followed by emesis $(n=35)$. Only small number of patients were diagnosed with febrile neutropnia $(n=5)$ and spinal cord compression $(n=2)$.

The most frequently reported symptoms were pain $(n=197$, $38.6 \%)$, gastrointestinal tract symptoms $(n=124,24.3 \%)$ and fever $(n=48,9.4 \%)$ as shown in Table 2 . The distribution of patients according to sites and types of pain is shown in Table 3. Dermatitis and emesis were the most frequent cancer treatment-related side-effects that prompted unplanned attendances (Table 4).

Overall, 95 patients (19\%) were admitted to the hospital for further management, 396 patients $(79 \%)$ were sent home and 10 patients $(2 \%)$ were referred to other hospitals for further management. Reasons for hospital admission, in order of frequency, were gastrointestinal symptoms (38\%), pain $(26 \%)$, infections $(12 \%)$, respiratory tract symptoms $(9 \%)$,
TABLE 4: Breakdown of symptoms secondary to cancer treatments that prompted unplanned visits by patients to the outpatients unit.

\begin{tabular}{lc}
\hline Symptoms & Number \\
\hline Chemotherapy-related side-effect & 17 \\
Emesis & 5 \\
Neutropenia & 4 \\
Numbeness & 3 \\
Diarrhoea & 3 \\
Anaemia & 1 \\
Oral mucositis & 33 \\
Total & \\
Radiotherapy-related side-effect & 15 \\
Dermatitis & 8 \\
Oral mucositis & 7 \\
Diarrhoea & 5 \\
Emesis & 4 \\
Burning micturition & 36 \\
Total & 69 \\
\hline Grand total &
\end{tabular}

neurological symptoms $(6 \%)$, urine retention $(3 \%)$, anaemia $(2 \%)$, fatigue $(2 \%)$, bleeding $(1 \%)$ and oral mucositis $(1 \%)$.

Of the 521 prescriptions issued during unplanned visits, analgesic medications were the most common (25\%), followed by antibiotics (22\%), proton pump inhibitors (15\%), hormonal medications such as tamoxifen, aromatase inhibitors and antiandrogens (12\%), intravenous fluids $(10 \%)$ and antiemetics $(8 \%)$. The average numbers of medicine prescribed for patient per unplanned visit was 1.2. Twenty out of thirty-two patients who had three or more medications prescribed per visit had comorbidities. Some patients with comorbidities needed a separate prescription for their long-term medications that are not available in the hospital pharmacy.

\section{Discussion}

As far as we know, this is the first study that assessed the prevalence, main reasons and the outcomes of unplanned visits by cancer patients to an outpatient oncology clinic in Sudan. We found that $30 \%$ of patients' attendances to the outpatient unit at the NCI during the study period were unplanned. These unplanned attendances add to the burden on already limited health resources and divert human resources, which are needed to manage patients making planned attendances.

Approximately two-thirds of our patients were female, which is similar to studies conducted in South Africa ${ }^{13}$ and Italy. ${ }^{15}$ This could be because breast cancer and gynaecological malignancies were the most common tumour sites in those countries. Studies from Turkey ${ }^{16}$ and the USA ${ }^{17}$ however, reported a higher proportion of male patients. This could be a reflection of a higher percentage of lung cancer cases in these countries, which are associated with male rather than female patients. The mean age (51.5 years) reported in this study is younger than that reported in similar studies conducted in South Africa (56.5 years), Italy (63 years) and Turkey ( 64.5 years). ${ }^{13,15,16}$ The younger mean age in this study is likely because of the higher proportion of breast cancer patients in this cohort. Sudanese women with breast cancer 
are on average younger compared with their counterparts from high-income countries. ${ }^{9,18}$

More than two-thirds (73.5\%) of our study population were from remote rural places and most of them were unemployed. Therefore, for them the financial implications of travelling to access healthcare at the NCI could be a huge burden. In our setting, cancer treatment is free for Sudanese patients at cancer treatment centres. Nevertheless, cancer patients need to pay for healthcare services at the primary and secondary healthcare levels. This might be a possible explanation of why a large proportion of our patients were self-referred and bypassing the primary care level and seek healthcare at cancer centre. Moreover, an effective patients' referral system in Sudan is lacking. Thus, implementing efficient referral systems between healthcare facilities in rural areas and cancer treatment centres, providing access to free healthcare services for cancer patients at primary healthcare facilities, involving general practitioners at primary and secondary healthcare levels in the follow-up of cancer patients and encouraging patients to visit their local facilities may help reduce unnecessary visits to specialised cancer centres. Studies from high-income countries documented that a large proportion of cancer patients have concerns about primary care physicians' expertise to conduct a thorough follow-up assessment for specific cancer issues or often felt that these physicians were unwilling to take on this responsibility. ${ }^{19,20}$

In this study, uncontrolled pain was the most frequent symptom $(39 \%)$ that prompted patients to make an unplanned visit to the outpatient unit. This finding is consistent with similar single institution studies from South Africa, Taiwan and Italy. ${ }^{13,21,22}$ Despite the existence of guidelines for cancer pain management, a systematic literature review of 26 studies from Asia, Europe and the United States showed that $43 \%$ of cancer patients do not receive adequate pain relief. ${ }^{23}$ In this study, the abdomen and bones were the most frequently reported sites of pain. A possible explanation is the high frequency of bone and liver metastasis as shown in Figure 1. Moreover, approximately one in five patients with cancer in this study had gastrointestinal tract (GIT) malignancies. In Sudan, common analgesics that are available for cancer patients are paracetamol, nonsteroidal anti-inflammatory drugs, tramadol and immediate-release morphine. Although pain medications at NCI are dispensed free of charge to cancer patients, the cost of travel represents a huge burden for the patients and their caregivers. In our limited resource setting, home care or hospice palliative care services are not available. Therefore, further studies are needed to find out the individual and organisational reasons for the high frequency of unplanned visits to outpatient unit by cancer patients with pain. Moreover, the adequacy of cancer pain management in our setting should be systematically evaluated.

Patients on active oncological treatment made about $50 \%$ of our cohort. These patients are at high risk of experiencing considerable treatment-related toxicities. At the study site, there is no dedicated clinic to follow patients on radiation therapy or chemotherapy. This may explain the higher frequency of this group of patients in this study. Therefore, avoidance of unplanned visits among patients on chemotherapy or radiation therapy may be possible by establishing a dedicated clinic to provide proactive follow-up and support to these patients.

In this study, $20 \%$ of patients visited the outpatient unit unplanned after missing their scheduled appointment. In various multispecialty clinics, the rate of missing planned appointment range from $15 \%$ to $30 \% .^{24,25,26}$ Transportation problems and patients' forgetfulness are reported as main reasons for missing appointment. ${ }^{26}$ It has been shown that reminder system such as text and voice message reminders in outpatient clinics are effective in improving patients' attendance across a range of healthcare settings and patient populations. ${ }^{27,28}$ Moreover, covering expense for transportation for poor patients may help alleviating the problem of transportation. Whether these factors are effective in reducing the rate of patients missing their appointment in our setting is unknown. Therefore, studies are needed to identify the burden and determinants of the missing planned appointment in our limited resource setting. The findings of these studies can help decision maker to develop strategies that are effective at improving appointment attendances.

We found a high rate of patients with multiple unplanned visits $(59 \%)$, including $12 \%$ of patients reporting five or more visits in the prior 3 months. This group of patients might have substantial unmet health needs. Therefore, further studies are warranted to find out possible reasons for this phenomenon. Moreover, the high rate of multiple unplanned visits highlights the importance of palliative care in oncology. Thus, improvement in the care of cancer patients with more pro-active palliative care can help to reduce this rate.

In this study, the rate of hospital admission was 19\%. Aprile et al. reported a $7 \%$ rate of hospital admission after an unplanned attendance in cancer patients. ${ }^{15}$ A study from Argentina reported $31 \%$ admission rate. ${ }^{29}$ Another study from Australia showed a very high rate $(83 \%)$ of hospital admissions. ${ }^{30}$ A possible explanation for variations in admission rates after an unplanned attendance by cancer patients could be because of the differences in study population. The study of McKenzie et al. included patients on chemotherapy, ${ }^{30}$ whereas this study included patients under active treatment (chemotherapy, hormonal or radiotherapy) and patients not on active treatment. The factors predicting hospital admission are beyond the scope of this study. However, previous studies suggest that predictors for hospitalisation include the number of symptoms, selected toxicities, distance from the hospital and visits near the end of life. ${ }^{15,31}$ Further research should 
focus on exploring the factors predicting hospital admission following unplanned attendances in our limited resource setting.

There are some limitations in this study. Firstly, symptoms have not been graded for severity. Secondly, although the data were prospectively collected and included a fairly large sample of cases from the only referral oncology institute in central Sudan, our study is a single institution so our findings and recommendations should therefore be generalised with the necessary caution.

\section{Conclusion}

This study shows high prevalence of unplanned visits by cancer patients to outpatient oncology unit of the NCI, located in central Sudan. Even though this is a single institution study, the NCI is the only oncology referral institute in central Sudan; therefore, the current data are the best indicator of the prevalence, main reasons for and outcomes of unplanned visits of cancer patients to outpatient oncology clinics within this region. Our analysis confirmed the significant magnitude of the phenomenon. The majority of the unplanned visits in this study were not true emergencies and fall within the scope of palliative management. Moreover, unplanned attendances add to the burden on already limited health resources. Therefore, dedicated strategies to avoid such visits are urgently needed. Uncontrolled pain was the most frequent symptom that prompted unplanned visit to the outpatient oncology unit. We therefore recommend that the adequacy of cancer pain management in our setting should be systematically evaluated and that effective cancer pain management programmes should be developed to reduce unplanned visits with pain as a presenting problem.

\section{Acknowledgements}

The authors would like to thank the outpatient unit team at the National Cancer Institute for assisting with the data collection.

\section{Competing interests}

The authors declare that they have no conflict of interest.

\section{Authors' contributions}

M.M.A.E. was the project leader. M.M.A.E., S.I.H.T., and M.M.A.M contributed to the design and implementation of the research, analysis of the results and writing of the manuscript.

\section{Funding information}

This research received no specific grants from any funding agency in the public, commercial or not-for-profit sectors.

\section{Data availability statement}

Data sharing is not applicable to this article as no new data were created or analysed in this study.

\section{Disclaimer}

The views and opinions expressed in this article are those of the authors and do not necessarily reflect the official policy or position of any affiliated agency of the authors

\section{References}

1. Bray F, Ferlay F, Soerjomataram I, Siegel RL, Torre LA, Jemal A. Global cancer statistics 2018: GLOBOCAN estimates of incidence and mortality worldwide for 36 cancers in 185 countries. CA Cancer J Clin. 2018;68(6):394-424. https://doi. org/10.3322/caac.21492

2. International Agency for Research on Cancer: Cancer tomorrow [homepage on the Internet]. [cited 2020 Jan 26]. Available from: https://gco.iarc.fr/tomorrow/ home.

3. Sloan FA, Gelband H,editors. The cancer burden in low-and middle-income countries and how it is measured. In Cancer control opportunities in low-and middle-income countries. Washington DC: National Academies Press; 2007; p. 69-105.

4. World Health Organization. WHO country cooperation strategy at a glance: Sudan. No. WHO/CCU/17.01/Sudan [homepage on the Internet]. Geneva: World Health Organization, 2017. Available from: https://www.who.int/countries/ sdn/en/.

5. Hamad HM. Cancer initiatives in Sudan. Ann Oncol. 2006;17(Suppl 8):viii32-viii36. https://doi.org/10.1093/annonc/mdl985

6. Elhassan MMA. Access to treatment for gynaecological malignancies in Sudan. Southern Afr J Gynaecol Oncol. 2018;10(2):21-23.

7. Ibrahim A, Rasch V, Pukkala E, Aro AR. Predictors of cervical cancer being at an advanced stage at diagnosis in Sudan. Int J Womens Health. 2011;3(1):385-389. advanced stage at diagnosis in Sudan.
https://doi.org/10.2147/IJWH.S21063

8. Abuidris DO,Weng HY, Elhaj AM, et al. Incidence and survival rates of ovarian cancer in low-income women in Sudan. Mol Clin Oncol. 2016;5(6):823-828. https://doi.org/10.3892/mco.2016.1068

9. Mariani-Costantini R, Elhassan MMA, Aceto MA, Mohamedani AA, Awadelkarim KD. Epidemiology, pathology, management and open challenges of breast cancer in Central Sudan: A prototypical limited resource African Setting. Breast Cancer. Phuc Van Pham, IntechOpen, 2017; 3-27. https://doi.org/10. 5772/67175

10. Elamin A, Ibrahim ME, Abuidris D, Mohamed KE, Mohammed SI. Part I: Cancer in Sudan-burden, distribution, and trends breast, gynecological, and prostate cancers. Cancer Med. 2015;4(3):447-456. https://doi.org/10.1002/cam4.378

11. Abdullah NE, Adam AA, Khalifa EH, et al. Nasopharyngeal cancer in Sudan: Epidemiology, clinical and histological characteristics. Clin Med Insights Ear Nose Throat. 2011;4(1):5-11. https://doi.org/10.4137/CMENT.S5825

12. Khougali HS, Albashir AA, Daffaalla HN, Salih M. Demographic and clinicopathological patterns of colorectal cancer at the National Cancer Institute. Saudi J Med Med Sci. 2019;7(3):146-150. https://doi.org/10.4103/sjmms.sjmms_138_18

13. Alleyne-Mike KR, Mohamed KEA, Abratt RP. Unscheduled visits to the oncology outpatient department: a guide for improving the efficiency of the health care outpatient department: a guide for improving the efficiency of the health care
framework. African J Cancer. 2014;6(1):32-39. https://doi.org/10.1007/s12558framework.

14. Lebel S, Tomei C, Feldstain A, Beattie S, McCallum M. Does fear of cancer recurrence predict cancer survivors' health care use? Support Care Cancer. 2013;21(3):901-906. https://doi.org/10.1007/s00520-012-1685-3

15. Aprile G, Pisa PE, Follador A, et al. Unplanned presentations of cancer outpatients: A retrospective cohort study. Support Care Cancer. 2013;21(2):397-404. https:// doi.org/10.1007/s00520-012-1524-6

16. Tanriverdi O, Beydilli $H$, Yildirim B, Karagoz U. Single center experience on causes of cancer patients visiting the emergency department in southwest Turkey. Asian Pac J Cancer Prev. 2014;15(2):687-690. https://doi.org/10.7314/apjcp.2014 15.2.687

17. Rivera DR, Gallicchio L, Brown J, Liu B, Kyriacou DN, Shelburne N. Trends in adult cancer-related emergency department utilization: An analysis of data from the Nationwide Emergency Department Sample. JAMA Oncol. 2017;3(10):e172450. https://doi.org/10.1001/jamaoncol.2017.2450

18. Elgaili EM, Abuidris DO, Rahman M, Michalek AM, Mohammed SI. Breast cancer burden in central Sudan. Int J Womens Health. 2010;2(1):77-82. https://doi. org/10.2147/ijwh.s8447

19. Kantsiper M, McDonald EL, Geller G, Shockney L, Snyder C, Wolff AC. Transitioning to breast cancer survivorship: perspectives of patients, cancer specialists, and primary care providers. J Gen Intern Med. 2009;24(Suppl 2):S459-466. https:// primary care providers. J Gen Intern
doi.org/10.1007/s11606-009-1000-2

20. Mao JJ, Bowman MA, Stricker CT, et al. Delivery of survivorship care by primary care physicians: The perspective of breast cancer patients. J Clin Oncol. 2009;27(6):933-938.

21. Tsai SC, Liu LN, Tang ST, Chen JC, Chen ML. Cancer pain as the presenting problem in emergency departments: Incidence and related factors. Support Care Cancer. 2010;18(1):57-65. https://doi.org/10.1007/s00520-009-0630-6

22. Foltran L, Aprile G, Pisa FE, et al. Risk of unplanned visits for colorectal cancer outpatients receiving chemotherapy: a case-crossover study. Support Care Cancer. 2014;22(9):2527-2533. https://doi.org/10.1007/s00520-014-2234-z

23. Deandrea S, Montanari M, Moja L, Apolone G. Prevalence of undertreatment in cancer pain. A review of published literature. Ann Oncol. 2008;19(12):1985-1991. https://doi.org/10.1093/annonc/mdn419 
24. Porta-Sales J, Codorniu N, Gómez-Batiste X, et al. Patient appointment process, symptom control and prediction of follow-up compliance in a palliative care outpatient clinic. J Pain Symptom Manage. 2005;30(2):145-153. https://doi. org/10.1016/j.jpainsymman.2005.03.008

25. Delgado Guay MO, Tanzi S, San Miguel Arregui MT,Chisholm G, De la Cruz MG, Bruera E. Characteristics and outcomes of advanced cancer patients who miss outpatient supportive care consult appointments. Support Care Cancer. 2014;22(10):2869-2874. https://doi:org/10.1007/s00520-014-2254-8

26. Crutchfield TM, Kistler CE. Getting patients in the door: Medical appointment reminder preferences. Patient Prefer Adherence. 2017;11(1):141-150. https:// doi.org/10.2147/PPA.S117396

27. McLean SM, Booth A, Gee M, et al. Appointment reminder systems are effective but not optimal: results of a systematic review and evidence synthesis employing realist principles. Patient Prefer Adherence. 2016;10(1):479-499. https://doi. org/10.2147/PPA.S93046
28. Car J, Gurol-Urganci I, de Jongh T, Vodopivec-Jamsek V, Atun R. Mobile phone messaging reminders for attendance at healthcare appointments. Cochrane Database Syst Rev. 2013:(12):Art. No.:CD007458 https://doi.org/10.1002/ 14651858.CD007458.pub3

29. Diaz-Couselo FA, O'Connor JM, Nervo A, et al. Non-scheduled consultation in oncologic patients. How many of them are true emergencies? An observational
prospective study. Support Care Cancer. 2004;12(4):274-247. https://doi. prospective study. Support Care
org/10.1007/s00520-003-0584-z

30. McKenzie $\mathrm{H}$, Hayes L, White $\mathrm{K}$, et al.Chemotherapy outpatients' unplanned presentations to hospital: A retrospective study. Support Care Cancer. 2011;19(7):963-969. https://doi.org/10.1007/s00520-010-0913-y

31. Barbera L, Taylor C, Dudgeon D. Why do patients with cancer visit the emergency department near the end of life? CMAJ. 2010;182(6):563-568. https:// doi:org/10.1503/cmaj.091187 